\title{
A New Approach to Implement High Strength 7075 Aluminum for Automotive Application
}

\author{
Cedric $\mathrm{Wu}^{1 *}$, Yudie Yuan ${ }^{1}$, and Rajeev Kamat $^{1}$ \\ ${ }^{1}$ Novelis Global Research and Technology Centre, 1950 Vaughn Rd NW, Kennesaw, GA, USA
}

\begin{abstract}
Aluminum alloys offer high specific strength than advanced high strength steels, making them preferred candidates for automotive light weighting. Among them, AA7075 aluminum alloy offers significantly higher strength than $5 \times x x$ and $6 x x x$ alloys and is considered an at tractive candidate by automotive OEMs for structural applications such as door intrusion beams, B pillars etc. There are several challenges in implementing AA7075, such as long artificial aging time to reach peak strength, joining method and corrosion resistance. In this study, an artificial aging practice that significantly reduces aging time was explored and its influence on mechanical properties of AA7075 was investigated in comparison with conventional peak age practice. In addition, this practice offers a potential solution for joining through self-piercing riveting Moreover, the effect of artificial aging on corrosion, specifically intergranular corrosion (IGC) and stress corrosion cracking (SCC) was evaluated. The results are discussed with in depth analysis and correlation with microstructure.
\end{abstract}

\section{Introduction}

Today, automotive OEMs are constantly pursuing ways to improve vehicle fuel economy to bring more value to customers and reduce carbon footprint to combat global warming and meet more stringent government regulations. Light weighting through implementing aluminum ranked among most preferred choices by automotive industry in a recent survey [1]. Aluminum alloys offer many benefits such as higher specific strength, better corrosion res istance in comparis on with steels.

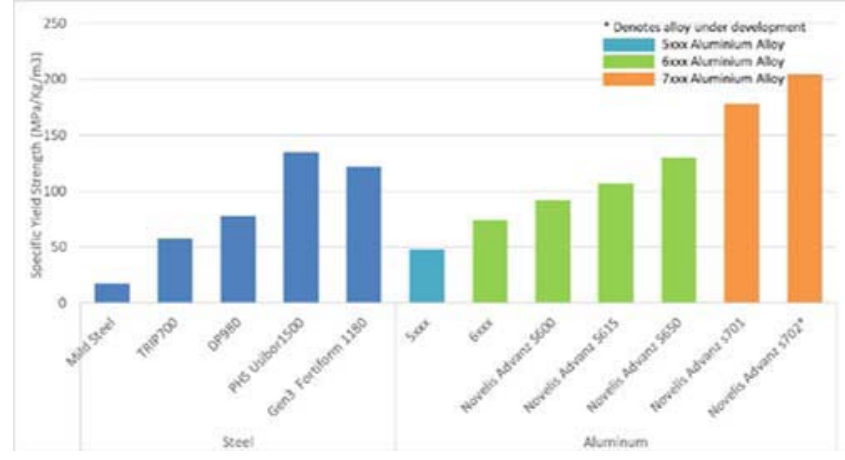

Figure 1: Comparis on of spe cific strength be tween aluminum alloys and steels.

$7 \mathrm{xxx}$ family of alloys is a high strength, heat treatable aluminum alloy primarily comprised of $\mathrm{Al}-\mathrm{Zn}-\mathrm{Mg}-\mathrm{Cu}$. It offers specific strength that are $10-30 \%$ higher than press hardened steels (PHS). Figure 1. Historically 7xxx alloys were widely used in the aerospace industry for applications like fus elage stringers and lower wing skins [2]. In recent years, new applications emerged in the automotive industry for components that requires high strength such as door intrusion beams, bumper reinforcements, B pillar outers and floor cross-members $[3,4,5]$. In order to fully utilize its high strength, $7 \mathrm{xxx}$ alloys need to be artificially aged to peak aged condition (T6 temper). As a result, the ductility of the alloy in T6 temper is reduced making it difficult to form in conventional room temperature stamping or joined mechanically. On the other hand the 7xxx alloy typically exhibits unstable T4 behavior leading to steady strength increase at room temperature. In order to improve AA7075's formability, extensiveres earch has been done to look into warm forming $7 \mathrm{xxx}$ aluminum $[6,7,8]$. In a warm forming scenario, the material is initially in peak aged condition, i.e. T6. $7 \mathrm{xxx}$ alloy at elevated temperature between $200^{\circ} \mathrm{C}$ to $260^{\circ} \mathrm{C}$ has shown improvement in formability compared to room temperature. However, exposure to high temperature leading to over aging, the component's mechanical properties are typically reduced and lower than peak aged condition. Alternatively, others have investigated hot stamping route for $7 \mathrm{xxx}$ aluminum. $[4,9]$ The concept of hot stamping aluminum is similar to that of hot stamped boron steel. The difference being $7 \mathrm{xxx}$ series aluminum starts in $\mathrm{F}$ temper, is solutionized in a furnace, subsequencially formed and quenched rapidly in a water cooled stamping die. It requires a post forming artifical aging cycle to achieve high strength. Conventionally, in order to achieve full hardened T6 temper, AA7075 alloy requires long artificial aging time (i.e. 24 hours). Such a long practicemakes implemention of AA 7075 difficult and can result in higher costespecially for high volume production. These challenges become limiting factors especially in automotive industry. Several heat treatment methods have been proposed and investigated by researchers such as T616 temper, high temperature preprecipitation (HTPP) Retrogression Re-aging (RRA) and 2 step aging aiming to improve the alloy's formability and

*Corresponding author: cedric.wu@novelis.com 
reduce artificial aging time $[10,11,12]$. Second area of concern with $7 \mathrm{xxx}$ aluminum usage comes from corrosion resistance which is preceived to be lower than 5xxx and $6 \mathrm{xxx}$ alloys. It has been reported in the literature [14-19] that $7 \mathrm{xxx}$ series aluminum alloys are susceptible to localized corrosion such as pitting, intergranular corrosion and stress corrosion cracking in aqueous solution containing particularly chloride ions. The corrosion behaviour of the 7xxx alloys was found to be strongly dependent on alloy composition and resulting microstructure, which is the evolution of material fabrication processes including thermo-mechanical history. The focus of this paper is to provide a comprehensive solution to implement Novelis Advanz ${ }^{\mathrm{TM}}$ s 701 (AA7075) alloy for complex automotive components through hot stamping process. An accelerated artifical aging practice tailored for automotive process is proposed. It will reduce total aging time and associated processing cost. In addition, the study investigates the microstrucual evolution of the material at various stages of artificial aging. As a result, s701 can achieve similar in service strength levels as conventional aging practice. Furthermore, the proposed artifical aging practice enables s 701 to be mechanically joined with self-piercing rivet (SPR). Additionally corrosion performance of the alloy, specifically IGC and SCC in the proposed temperwas investigated.

\section{Experiment}

The material used in this article was Novelis Advanz ${ }^{\mathrm{TM}}$ s 701 alloy. Its chemical composition falls within AA7075 range, (Table 1) presented in weight percent.

Table 1 Chemical Composition of Novelis Advanz ${ }^{\text {TM }}$ s 701

\begin{tabular}{|c|c|c|c|c|c|c|c|c|c|}
\hline & $\mathrm{Si}$ & $\mathrm{Fe}$ & $\mathrm{Cu}$ & $\mathrm{Mn}$ & $\mathrm{Mg}$ & $\mathrm{Cr}$ & $\mathrm{Zn}$ & $\mathrm{Ti}$ & $\mathrm{Al}$ \\
\cline { 2 - 9 } & 0.4 & 0.5 & $1.2-$ & 0.3 & $2.1-$ & $0.18-$ & $5.1-$ & \multirow{2}{*}{0.02} & Rem. \\
AA7075 & 0.0 & & 2.0 & & 2.9 & 0.28 & 6.1 & & \\
\hline
\end{tabular}

S701 alloy was DC cast, homogenized, scalped, hot rolled and cold rolled to $2.0 \mathrm{~mm}$ final gauge in Novelis Korea Plant. Lab evaluations were carried out at Novelis Global Research and Technology Centre(NGRTC).

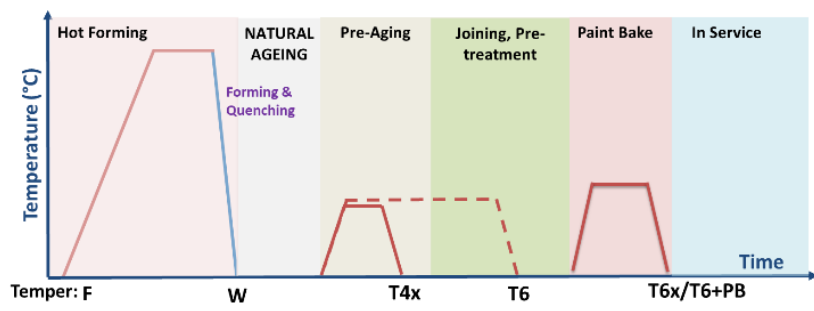

Figure 2: Schematic of s701 alloy hot stamping process flow path with 2 artificial aging routes: T4x to T6x and standard T6 to T6+PB.

Starting with an as cold rolled $\mathrm{F}$ temper, the material was solutionis ed at $480^{\circ} \mathrm{C}$ for 5 minutes followed by quenching in temperature controlled water bath to simulate quench rate $>350^{\circ} \mathrm{C} / \mathrm{sec}$ similar during hot s tamping process [13]. The material was allowed to naturally age in ambient temperature for 1 week before artificially aging to vanious tempers. Figure 2 shows potential hot stamping process flow path for s701 alloy with both conventional and accelerated artificial aging. Tempers and heat treatment conditions are defined below:

- F: As fabricated sheet metal after hot rolling and cold rolling.

- W: Solutionised and freshly quenched, unstable temper.

- T4x: Artificially aged between $100-120^{\circ} \mathrm{C}$ for 1 hour, under-aged and intermediate temper.

- T6: Artificially aged at $125^{\circ} \mathrm{C}$ for 24 hours, peak aged.

- T6x: T4x followed by aging at $180^{\circ} \mathrm{C}$ for 0.5 hour, accelerated aging, in service temper.

- T6+PB: T6 followed by aging at $180^{\circ} \mathrm{C}$ for 0.5 hour, conventional practice, in service temper.

Full size tensile specimens were tested as per ASTM B557 to determine various tempers' mechanical properties. Metallurgical samples were cut parallel to rolling direction and mounted in long transverse direction. Mounted samples were ground, polished using standard metallographic sample preparation procedure. Mounted samples were etched using Barker's agent to reveal the grain structure. Mounts were observed under a Zeiss Axio metallurgical micros cope. A polarized filter was us ed to reveal the grain structure. Scanning Electron Microscopy (SEM) was done using a Philips XL30 S FEG-SEM at an operating voltage of $20 \mathrm{kV}$. Transmission Electron Microscopy (TEM) samples were prepared using electro polishing at Natural Resources Canada. Samples were analysed using FEI's Tecnai Os iris TEM equipped with X-FEG gun at $200 \mathrm{keV}$. Samples were tested for intergranular corrosion (IGC) as per ASTM G110 specification with immersion time of 24 hours. Stress corrosion cracking (SCC) was tested as per ASTM G44 alternate immers ion test in $3.5 \% \mathrm{NaCl}$ solution at $0 \%$ and $80 \%$ yield stress for a duration of 40 days. Samples were pulled after completion of SCC test to determine the residual stress as per ASTM G139. SelfPiercing Rivet (SPR) tests were conducted at Stanley® joining technology laboratory in Troy, MI. The stack up in this study comprises of $2.0 \mathrm{~mm}$ Novelis Advanz ${ }^{\mathrm{TM}} \mathrm{s} 615 \mathrm{~T} 4$ material on top and $2.0 \mathrm{~mm} \mathrm{Advanz}{ }^{\mathrm{TM}} \mathrm{s} 701$ in T6,T4x with 0 days and 32 days of natural aging respectively at the bottom of the stack. Through multiple preliminary trials, a C5.3x6.0 H4 semi-tubular rivet and M260 468 die combination was deemed to have given the best result for this particular stack up and selected.

\section{Results and Discussion}

\subsection{Microstructure}

Figure 3 shows s701 alloy's microstructure in F temper and T6 temper res pectively.

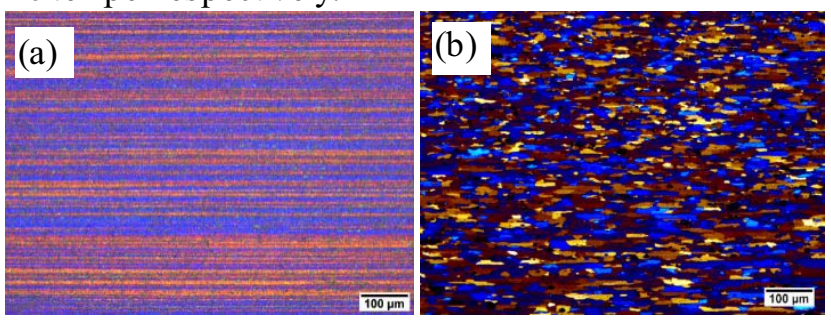

Figure 3: Barker's e tched optical metallography of s701 in (a) $F$ and (b) T6 temper. 
The alloy in its initial state of a typical aluminum hot stamping process is F temper, which has deformed grains with fibrous structure shown in Figure 3a. During the solution heat treatment, the alloy was brought to above its solvus temperature where the coarse precipitates formed during processing were effectively dissolved into solid solution and the material recrys tallized as shown in Figure 3b.For any quaternary Al-Zn-Mg-Cu alloy system, it typically comprises a complex system of precipitation phases and constituent particles. Primary strengthening phase in 7075 alloy is $\mathrm{M}$ phase $\left(\eta=\mathrm{MgZn}_{2}\right)$. Its precursor GP zone and metastable semi-coherent $\eta$ ' phase are the main governing precipitates responsible for high strength [14]. In $\mathrm{Cu}$ bearing 7xxx alloys such as s701, $\mathrm{Cu}$ may replace $\mathrm{Zn}$ atoms to form $\eta-\mathrm{Mg}(\mathrm{Zn}, \mathrm{Al}, \mathrm{Cu})_{2}$ [15]. In addition, there are other undesired phases present. For example, $\mathrm{T}$ phase, nominally $\mathrm{Al}_{2} \mathrm{Mg}_{3} \mathrm{Zn}_{3} ; \mathrm{S}$ phase, nominally $\mathrm{Al}_{2} \mathrm{CuMg} ; \theta$ phase, nominally $\mathrm{Al}_{2} \mathrm{Cu}$ and $\mathrm{Z}$ phase, norminally $\mathrm{Mg}_{2} \mathrm{Zn}_{11}$. The amount of major equillibrium phases $(\mathrm{M}, \mathrm{T}, \mathrm{S})$ are essentially determined by factors such as $\mathrm{Zn}: \mathrm{Mg}$ ratio, casting practice homogenization temperature and time, cooling rate and artificial aging temperature [16]. Besides precipitates, there are also coarse constituent particles such as $\mathrm{Mg}_{2} \mathrm{Si}$ and $\mathrm{Al}_{7} \mathrm{Cu}_{2} \mathrm{Fe}$, which originated in casting process. These phases are insoluble and incoherent to the matrix. Such coarse constituents are in size range of 5-30 microns, depending on processing conditions. They are visible under microscopy as illustrated in Figure 4. These coarse cons tituents are insoluble during solutionization step of hot stamping process and are detrimental to the materials' corrosion behaviour[17].

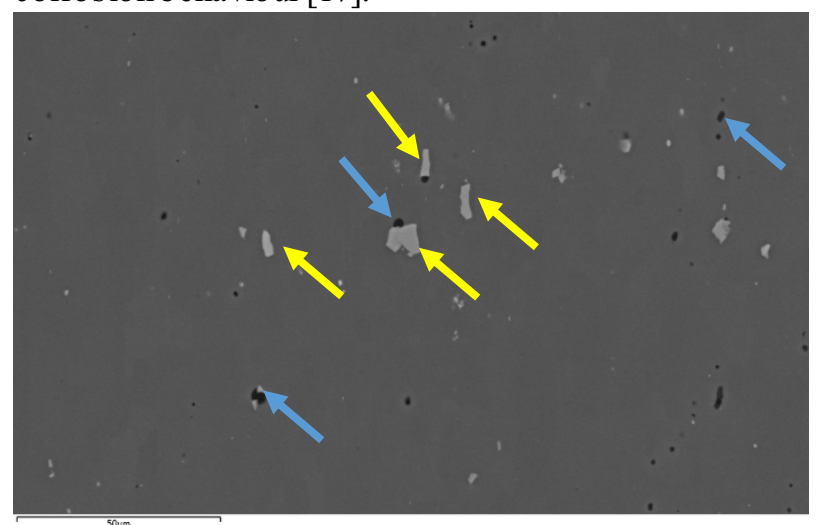

Figure 4: SEM image of s701 in T6 temper, showing constituent particles. Blue arrow in dicates $\mathrm{Mg}_{2} \mathrm{Si}$ and yellow arrow indicates $\mathrm{Al}_{7} \mathrm{Cu}_{2} \mathrm{Fe}$.

The precipitation sequence in AA7075 alloy can be described as:

SSSS $->$ Clusters $->$ G.P. zone $->\eta$ ' $->\eta$.

In its maximum strength condition, G.P. zones are in the size of 20 to $35 \AA$ in diameter along with metastable $\eta$ ' transition precipitate. Increase in the natural aging interval or preaging at a lower temperature can promote the development of G.P. zones, consequently provide a finer precipitate structure and facilitate the alloy reach peak strength when artificially aged. Chrome containing dispersoids, nominally $\mathrm{Al}_{7} \mathrm{Cr}$ are often found along the grain boundaries, they are typically triangular, round or rod in shape, 80-120nmin size.(Figure 7) These dispersoids can pin the grain boundaries and in hibit recrystallization during high temperature processing. Chrome containing dispersoids would increase the alloy's fracture toughness better than Mn based dis persoids. [18]

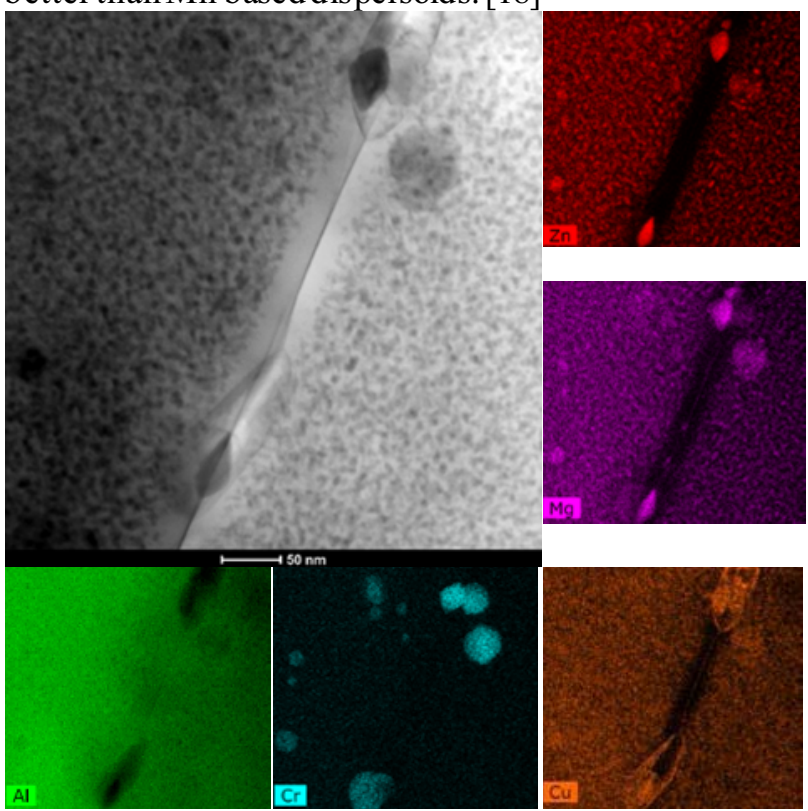

Figure 5: HAADF and elemental map showing typical s701 microstructure in $\mathrm{T} 6+\mathrm{PB}$ condition.

Figure 5 shows High Angle Annular Dark-Field Imaging (HAADF) of typical s 701 alloy microstructure in T6+PB temper. $\mathrm{Al}_{7} \mathrm{Cr}$ dispersoids can be seen at the grain boundaries. Coarse $\eta-\mathrm{Mg}(\mathrm{Zn}, \mathrm{Al}, \mathrm{Cu})_{2}$ was found to be discontinuously nucleated on $\mathrm{Al}_{7} \mathrm{Cr}$ dispersids. High volume density of $\eta$ 'precipitates can be obvserved in the matrix. Precipitation free zone (PFZ) are measured 30-40 nm in width.

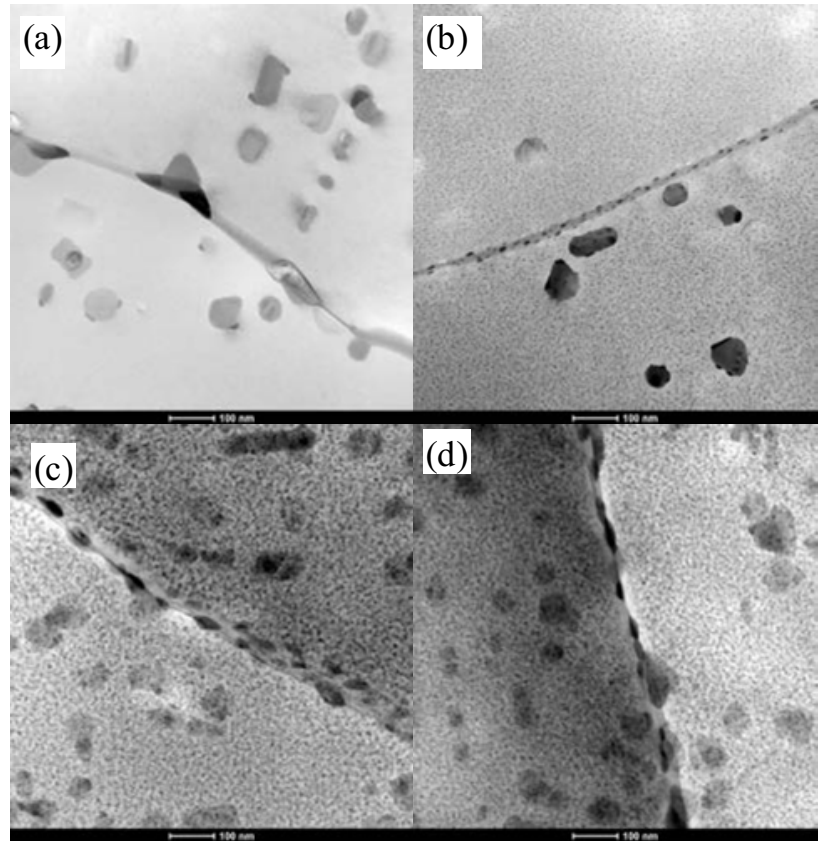

Figure 6: Bright Field (BF) image of typical s701 microstructure under various heat tre atment conditions. (a) W temper; (b) T4x temper; (c) T6x te mper and (d) Standard T6+PB temper. 


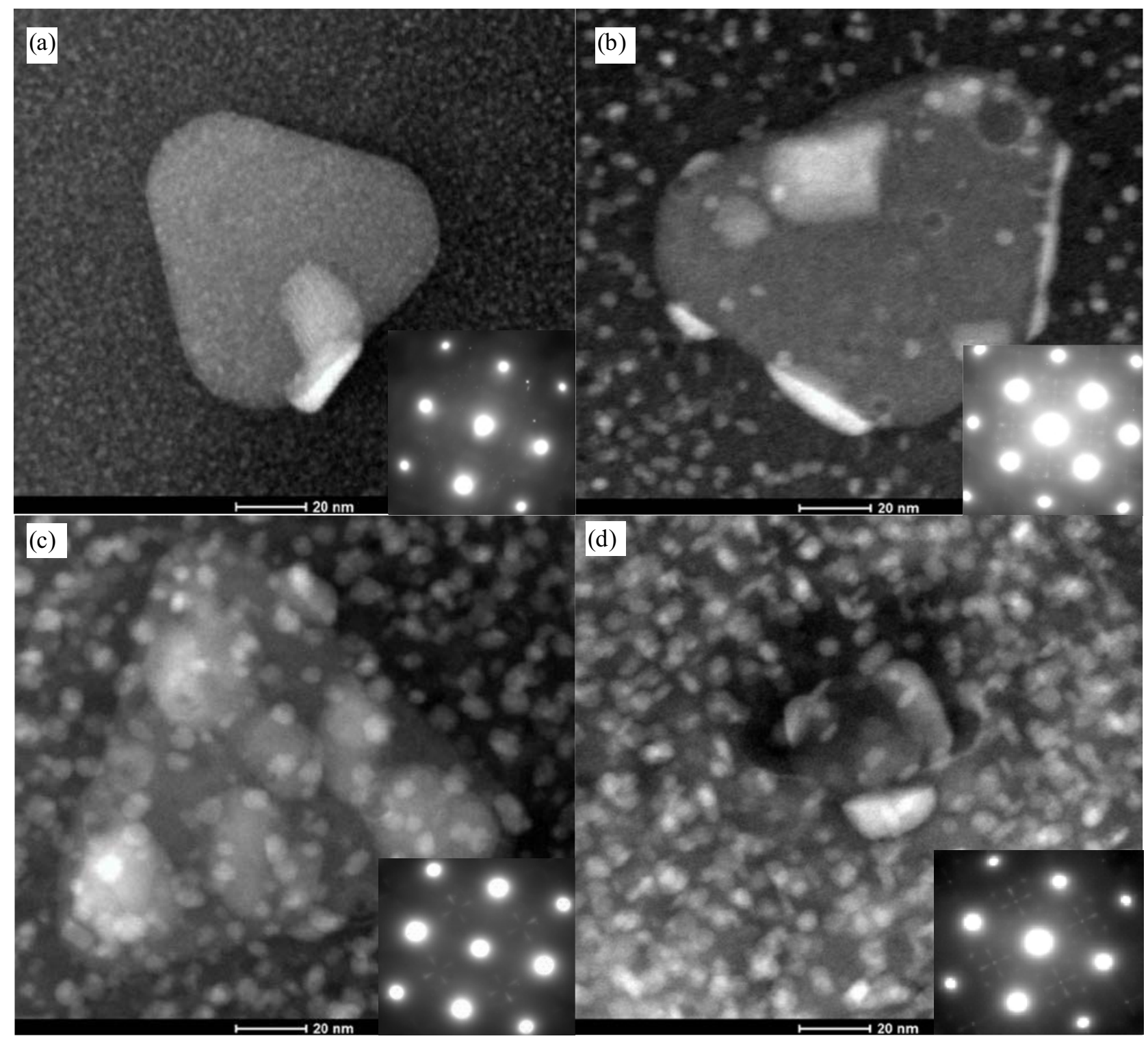

Figure 7: HAADF with a Chrome containing dispersoid in the centre of field of view and $S$ AD obtain ed along [001] zone axis of (a) W temper+1 month of NA s701, (b) T4x temper, (c) T6x te mper and (d) Standard T6+PB temper.

Figure 6a shows $\mathrm{s} 701$ microstructure in $\mathrm{W}$ temper, The grains are free of any precipiates since all the solute were effectively dissolved into solid solution during solution heat treatment. However, high resolution images shows clusters and early stage nano size GP zone are present (Figure 7a) in the matrix. The clusters and GP zones formed after hot stamping process with natural aging, in this case 1 month of NA. In addition, the quench rate used during preperation of the sample resembles that of during hot stamping, there are evidence of $\mathrm{Al}_{7} \mathrm{Cr}$ dispersoids at grain boundary along with coarse $\eta-\mathrm{Mg}(\mathrm{Zn}, \mathrm{Al}, \mathrm{Cu})_{2}$ phase. Artificial aging of the material brings the alloy into $T 4 x$ temper. The positions of super lattice reflection of GP zones and $\eta$ ' precipitates are presented in a four folded pattem at the vicinity of $2 / 3\{220\}$ positions [19]. The super lattice reflections were first observed in $\mathrm{T} 4 \mathrm{x}$ condition. The precipitates also became more evident and emerges from the matrix as shown in Figure $6 \mathrm{~b}$. High magnification image show $\eta^{\prime}$ precipitates in the range of $5 \mathrm{~nm}$, as illustrated in Figure $7 \mathrm{~b}$. Figure 8 shows high resolution TEM with beam $\|[001]$, showing $\eta$ ' precipitates. The transition stateprecipitate is coherent to the matrix making them the primary strengthening mechanis mfor $\mathrm{7} 701$ alloy.

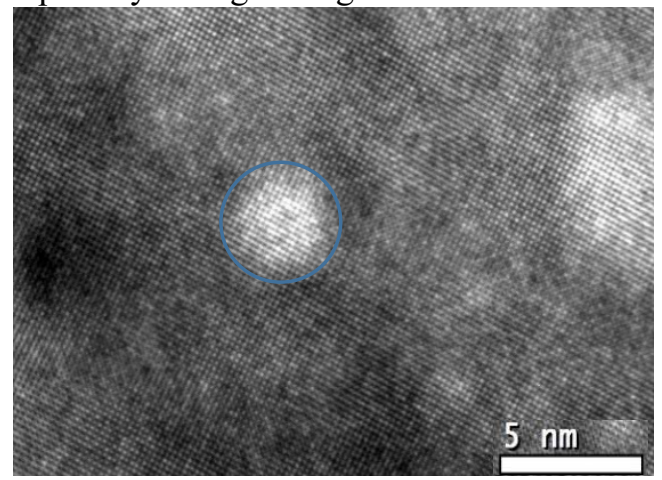

Figure 8: HRTEM with beam \|[001], showing T4x s701 sample's $\eta$ ' precipitates coherent with matrix.

The formation of GP zones and $\eta$ ' transition phases during first aging step to a certain size and distribution is critical to the alloy's next aging response. They would act as precursor, allowing precipitates to transform during 
subsequent artificial aging process. Figure $6 \mathrm{c}$ and d compares T6x temper with standard T6+PB temper, both presumably represent the material in servicecondition. One can no longerdelineate between the two conditions froma microstructural level. In both conditions, grain boundaries are well decorated with discontinuous $\eta$ ' precipitation. PFZ are in the size of 40-50 $\mathrm{nm}$. Precipitates are approximately 5-10 $\mathrm{nm}$ in size, larger and higher number density compared to earlier stage tempers. Coarse $\eta$ $\mathrm{Mg}(\mathrm{Zn}, \mathrm{Al}, \mathrm{Cu})_{2}$ phases are found to have a tendency to nucleate on $\mathrm{Al}_{7} \mathrm{Cr}$ in all four tempers examined. The coarse precipitates are larger size than they are in the matrix and grew during aging. These coarse precipitates are incoherent to the matrix and do not contribute to strengthening of the alloy. Furthermore, it would reduce the amount of solute available in the matrix and hinder the alloy's aging response. It should be pointed out that such phenomenon would vary depending on quench rate during hot stamping process. If the quench rate is reduced further, undesirable coarse precipitates could become more evident. Having more of these coarse precipitates at the grain boundary is detrimental to the alloy's strength at peak age. These coarse precipitates are heterogeneously distributed along grain boundaries makes the alloy prone to corrosion attack. Thus, attaining a faster quench rate during hot stamping of AA7075 aluminum alloy is desirable to avoid the nose of the CCT curve, resulting in higher strength and better corrosion resistance. Quench rate from a hot stamping process with water cooled die could achieve $350 \sim 400^{\circ} \mathrm{C} / \mathrm{sec}$ which is sufficient for AA 7075 [4].

\subsection{Mechanical Properties}

The beauty of the proposed accelerated aging practice is the ability to achieve strength comparable to conventional $\mathrm{T} 6+\mathrm{PB}$ process route while significantly reduce the amount of artificial aging time after hot stamping. Figure 9 compares mechanical property of s 701 material in various tempers. F temper properties are governed by the upstream processing conditions such as homogenization, hot rolling, hot band coiling temperature, the amount of reduction during hot and cold rolling etc. F temper has the lowest mechanical property in terms of elongation due to the fibrous deformation microstructure and coarse uncontrolled precipitates. W temper is an unstable temper after hot stamping process. Its microstructure would continue to change as previously discussed. Therefore, the mechanical property of $\mathrm{s} 701$ alloy would continue to increase overtime as the material continues to naturally age. The data presented here is material's mechanical property immediately after solutionization, i.e. within 24 hours. The alloy in the $\mathrm{W}$ temper has a low yield strength of $240 \mathrm{MPa}$ with $20 \%$ total elongation. However, the unstable nature of the alloy making it hard to utilize it in standard stamping operations. It would be possible to take advantage of the good ductility if the material can be stabilized. After extensive research and experiment at Novelis, practice of $100-120^{\circ} \mathrm{C}$ for 1 hour was selected as $\mathrm{T} 4 \mathrm{x}$ heat treatment for $\mathrm{s} 701 . \mathrm{S} 701$ in its $\mathrm{T} 4 \mathrm{x}$ condition has intermediate mechanical properties that fall between $\mathrm{W}$ and its final in service temper T6x. The initial yield strength in T4x is about $400 \mathrm{MPa}$. Total elongation of the alloy is $18 \%$, which only exhibits s light decrease in comparison with $\mathrm{W}$ temper. Thus providing an opportunity for mechanical fastening such as SPR, discussed in section 3.4. The proposed accelerated aging practice (T6x) bring the alloy to T6x temper by utilizing paint bake cycle in automotive BIW production process. It will quickly grow the precipitate size and distribution to an optimumlevel and resulted in having similar microstructure with the conventional T6+PB condition. As a result, its mechanical properties are similar to that of a standard T6+PB practice, in terms of yield strength, tensile strength and elongation.

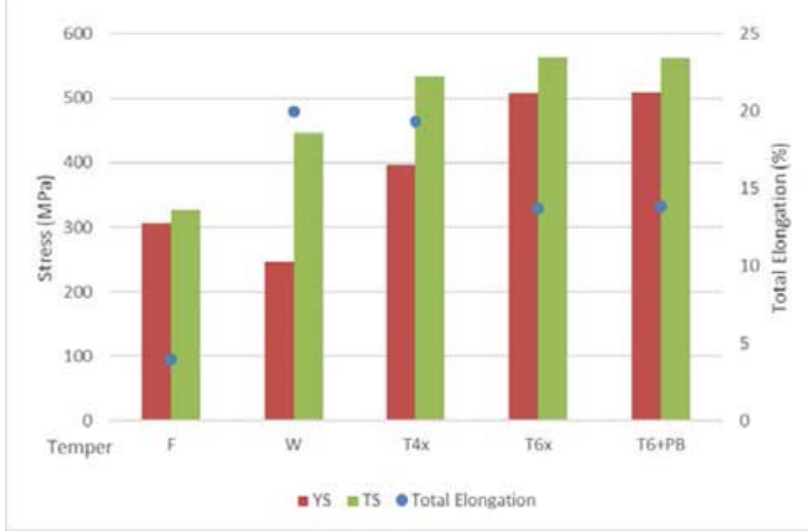

Figure 9: Mechanical properties of $\mathrm{s} 701$ in various tempers.

In previous micros tructural analysis, it was obvious that the first heat treatment step transitioned clusters into GP zones and nano scale $\eta$ ' precipitates. The precipitates are still in transition period with smaller size and lower number density than T6x. It suggests that the material may have a propensity to continue to naturally age in $\mathrm{T} 4 \mathrm{x}$ condition, similar to a $6 \mathrm{xxx}$ alloy. Figure 10 shows comparis on of s 701 natural aging behavior between $\mathrm{W}$ temper and T4x temper for up to 90 days. $\mathrm{S} 701$ alloy ages more rapidly in $\mathrm{W}$ temper than it does in T4x condition (Figure 10).

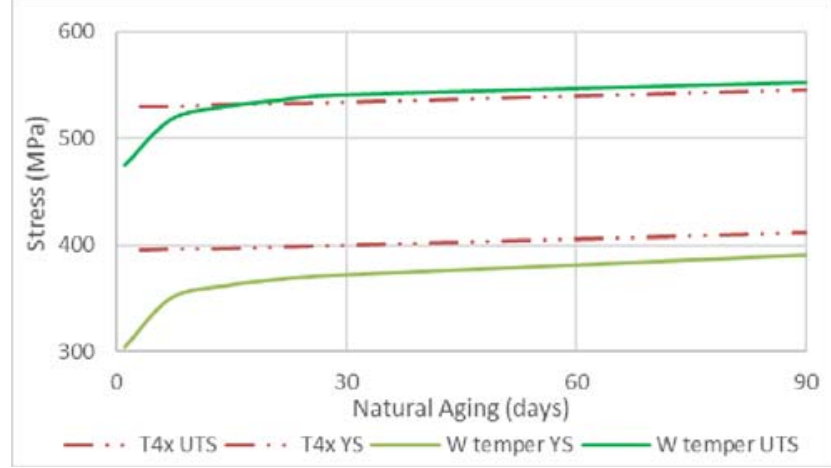

Figure 10: Natural aging trend comparison between $T 4 x$ and W temper

Within a 90-day period, its yield strength and tensile strength increased by 87 and $77 \mathrm{MPa}$ respectively. In contrast, within the same time frame s 701 in T4x condition, yield strength and tensile strength both increased by 15 $\mathrm{MPa}$. Thus it is evident s 701 in T4x is a stables state. Its mechanical properties can be guaranteed with good ductility to allow certain mechanical joining/deformation process. In a typical automotive production scenario, Body In White (BIW) will go through multiple coating steps such 
as electro-coat (eCoat), top coat etc. The total paint bake time and temperature combination would vary between different OEMs. In addition, there could be some temperature variations depending on the location and adjacency of the parts. An artificial aging of $180^{\circ} \mathrm{C}$ for 30 minutes is a simulated single step paint bake cycle intended for laboratory use. Furthermore, during production, the paint line maybe stalled/slowed due to mechanical issues. The BIW may require rework to remove minor imperfections and need to be sent through the paint line again. Thus, the robustness of the structural components to meet target mechanical properties under extended exposure at paint bake temperature becomes critical. Figure 11 shows simulated T6x temper going through additional paint bake cycles up to 2 times. It maintained over $500 \mathrm{MPa}$ in yield strength and did not exhibit any strength loss despite experiencing multiple paint bake cycles. The finding shows that proposed accelerated aging practice has similar level of robus tness as conventional 7075 T6 [11].

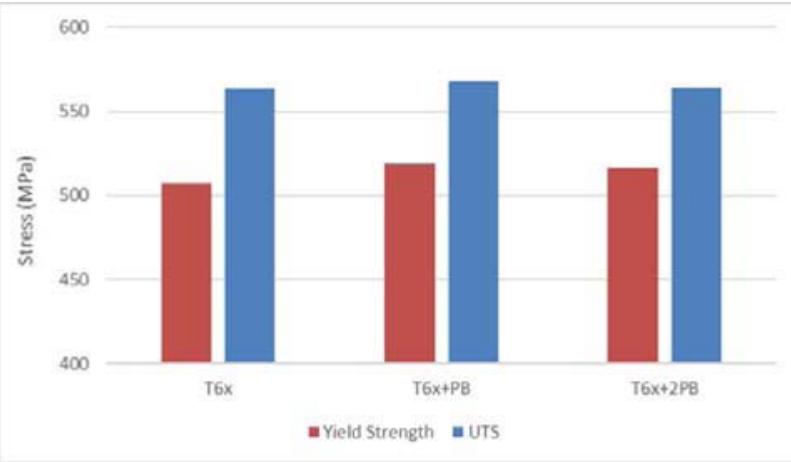

Figure 11: s701 multiple paint bake response after proposed T6x temper.

\subsection{Corrosion Results}

S701 alloy would only be exposed to corrosive environment in its final in-service temper, i.e. T6x or $\mathrm{T} 6+\mathrm{PB}$, therefore corrosion testing was carried out in these tempers. Two specific types of corrosion tests were conducted: Intergranular corrosion res is tance (IGC) and Stress corrosion cracking (SCC). IGC of s 701 alloy in simulated service temper T6x and T6+PB was studied by immersion test per ASTM G110. The cross-section of specimens subjected to 24 hour full exposure is shown in Figure 12.

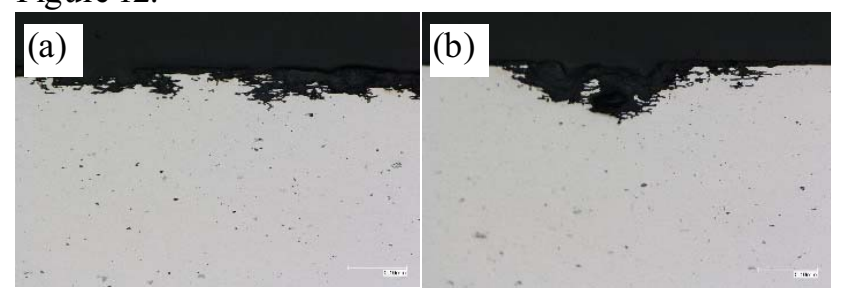

Figu re 12: Metal lographic cross section of $\mathbf{s} 701$ in (a) stan dard T6+PB and (b) T6x condition after 24 hoursimmersion test.

Corrosion depth was meas ured and summarized in Table 2. Overall, the two tempers behave similarly in IGC performance with T6x temper showing slightly higher in corrosion depth. The corrosion depth exhibited for $\mathrm{s} 701$ is comparable to that of a high $\mathrm{Cu} 6 \mathrm{xxx}$ alloy used in automotive applications, presumably can fulfill IGC acceptance criteria in terms of maximum and average corrosion depth.

Table 2: S u mmary of IGC results in G110 test ( $24 \mathrm{~h}$ exposure)

\begin{tabular}{|c|c|c|c|c|}
\hline \multirow{2}{*}{ Alloy } & \multirow{2}{*}{ Temper } & \multicolumn{3}{|c|}{ Corros ion depth evaluation } \\
\cline { 3 - 5 } & $\begin{array}{c}\text { Max. } \\
\mu \mathrm{m}\end{array}$ & $\begin{array}{c}\text { Average, } \\
\mu \mathrm{m}\end{array}$ & $\begin{array}{c}\text { STDEV, } \\
\mu \mathrm{m}\end{array}$ \\
\hline \multirow{2}{*}{ s701 } & $\mathrm{T} 6+\mathrm{PB}$ & 84 & 41 & 17 \\
\cline { 2 - 5 } & $\mathrm{T} 6 \mathrm{x}$ & 103 & 57 & 24 \\
\hline
\end{tabular}

The alternate immersion test (G44) for characterizing SCC ended with no specimens fracturing in-situ during 40 days exposure. Therefore, strength loss with respect to the bulk material property is used to compare SCC res istance for two tempers, as shown in Figure 13. The average residual strength in specimens stressed to $80 \%$ of their yield strength showed very little drop $(\sim 3 \%)$ in comparison with the uns tressed on es for either temper (T6x or T6 + PB).

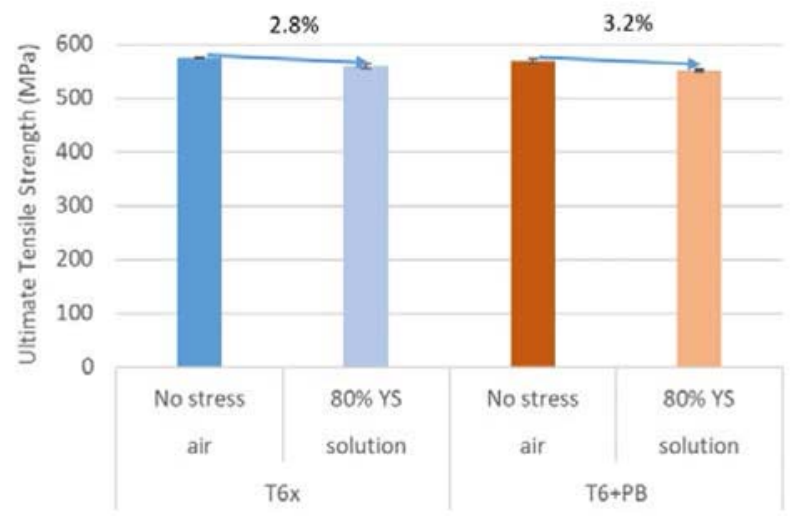

Figure 13: Comparis on of ultimate tensile strength between T6x and T6+PB specimens before and after SCC test

The fracture surfaces of the specimens in air and in corros ive $\mathrm{NaCl}$ solution were examined by SEM. Figure 14 displays representative fractographies of T $6 \mathrm{x}$ and $\mathrm{T} 6+\mathrm{PB}$ tempers tested in air and in solution respectively. In air, the specimens of T6+PB and T6 temper pos sess predominant dimple fracture surface, characterized by ductile fracture appearance. Representative SEM fractography of the $\mathrm{T} 6+\mathrm{PB}$ is shown in Figure 14a, where cup and cone dimples with varying sizes are observed. Figure $14 \mathrm{~b}$ was taken from the exact same location under SEM but in backscattered electron (BSE) mode that can detect secondary particles present in dimples. It can be seen from that the main dimples (e.g. regions indicated by red arrows in Figure $14 \mathrm{a}, \mathrm{b}$ are traces of voids formation around second-phase particles; EDS analysis determined that these bright particles are $\mathrm{Cu}$ and $\mathrm{Fe}$ containing ones (e.g. $\mathrm{Al}_{7} \mathrm{Cu}_{2} \mathrm{Fe}$ ). Figure $14 \mathrm{c}-\mathrm{f}$ shows fractographs of the specimens in $\mathrm{T} 6+\mathrm{PB}$ and $\mathrm{T} 6 \mathrm{x}$ tempers tested in solution. In contrast to specimens tested in air, the T6+PB and T6x undergone alternate immersion in $3.5 \% \mathrm{NaCl}$ solution for 40 days show a completely brittle fracture surface that is characterized by inter-granular cracks and a mixture of transgranular and intergranular cleavage fracture. Furthermore, some corrosion products are als o visible as 
brighter particles due to charging on the fracture surface (orange arrows in Figure 14c and f).

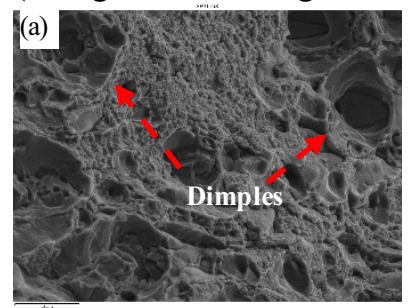

T 6+PB tested in air (SE)

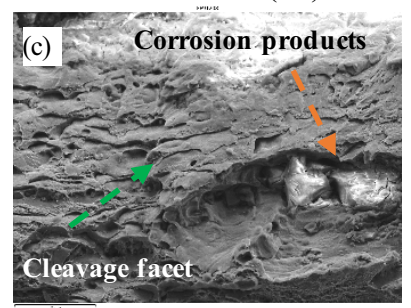

T $6+\mathrm{PB}$ tested in solution

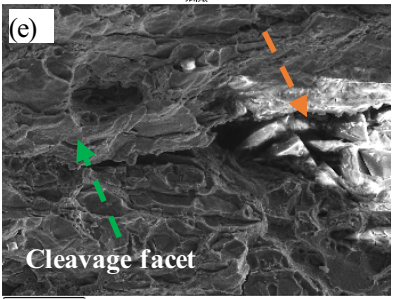

T 6x tested in solution

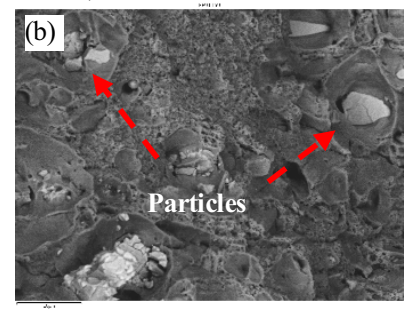

T $6+\mathrm{PB}$ tested in air $(\mathrm{BSE})$

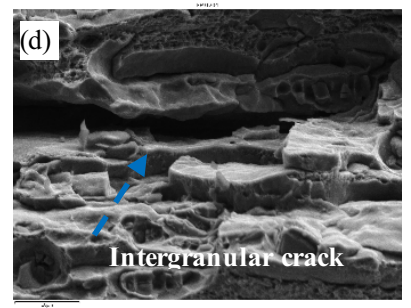

$\mathrm{T} 6+\mathrm{PB}$ in solution

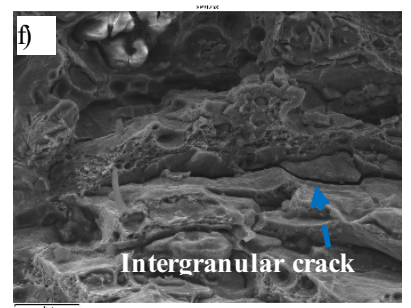

$\mathrm{T} 6 \mathrm{x}$ tested in solution
Figure 14: SEM fractograph s of the s701 in T6 $x$ and T6+PB te mpers tested in air and in solution (per ASTMG44 for 40 days)

The intergranular cracking for the temper T6+PB and T6x suggested that the grain boundaries acted as the most preferential and active corrosion path for stress corrosion cracking due to the dis solution of densely distributed $\eta$ ' precipitates distributed along the grain boundaries (Figure $14 \mathrm{c}$ and $\mathrm{d})$. It is worth noting here again that both the T6+PB and T6x specimens passed the defined SCC-G44 test and only showed less than 5\% drop in ultimate strength. Therefore, it is to be inferred that the T6x temper exhibits similar SCC resistance to the T6+PB temper. Improved localized corrosion (such as pitting) and SCC res is tance in overaged temper as compared to peak-edged $\mathrm{T} 6$ temper are widely reported [20,21, 22]. In addition, the material were tested in bare condition, with relatively high stress level of $80 \%$ yield stres s. In reality, the components in BIW would have an layer of eCoat which will provide an extra layer of protection. Proper stress level need to be determined based on component function and simulated drive cycle load cas es. Potential exposure to corrosive environment would als o be different depending on location of the component in a vehicle.

\subsection{SPR Joining}

Self-piercing rivet (SPR) is a joining method commonly used in aluminum intensive and mixed materials vehicles. However, conventional s 701 alloy in standard T6 temper was challenging to join using SPR due to low ductility [23]. Since s701 material demonstrated a stable mechanical property in its T4x condition with good elongation, it opens an opportunity for it to be SPR joined. For the ease of production, in most SPR applications, the desired stack up is with a thicker and more formable alloy on the bottom of the stack. Previous experience suggests it was easier to form a joint with 7xxx alloys located on the top of stack. Hence, the current study emphasized on a solution having s701 alloy positioned at the bottom stack. When s 701 is riveted in T6 condition, the rivet buckled after it pierced through the top layer into the high strength $\mathrm{s} 701$ on the bottom stack, as illustrated in Figure 15a,b. The material also developed button crack due do its poor ductility. Under this scenario the SPRjoint was considered as unacceptable. However, when the temper of s 701 on the bottom stack changed to T4x temper in Figure $15 \mathrm{c}-\mathrm{f}$, due to the alloy's improved ductility, there was no sign of button crack. Cross-s ection reveals the rivet has good amount of interlock $\geq 0.2 \mathrm{~mm}$ and no concern of bottom thinning. Gaps under the rivet head were completely filled, alleviated corrosion concerns with potential mois ture trapped underneath. The tests were repeated at several time intervals from 0 day to up to 32 days of natural aging to address concern of changing properties in $\mathrm{T} 4 \mathrm{x}$ and all resulted in formation of a good joint.

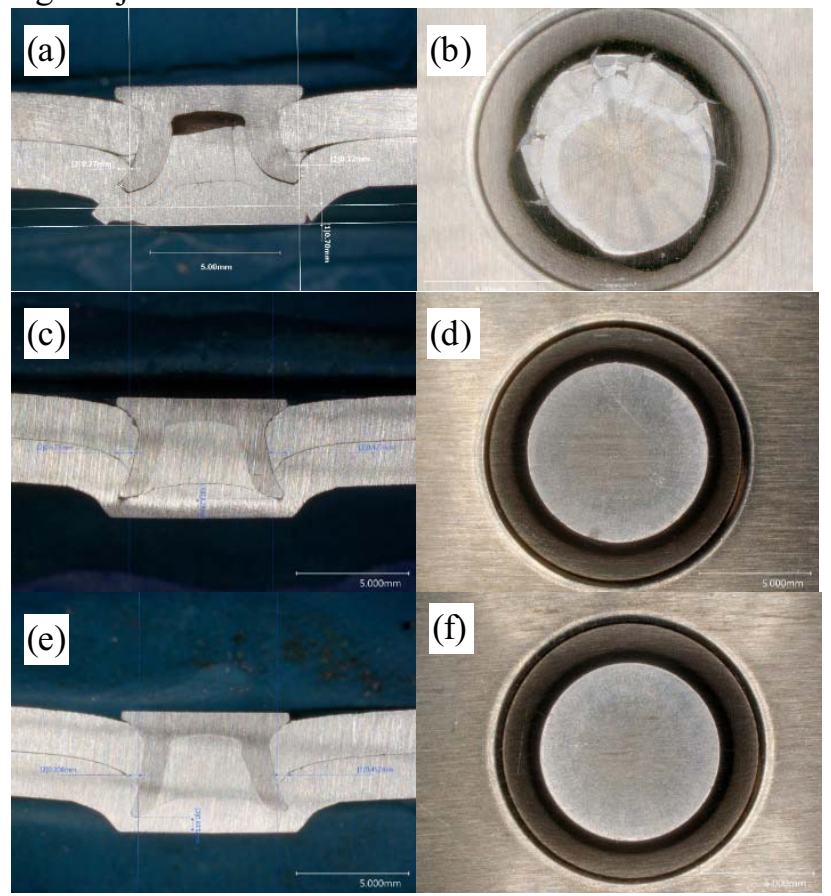

Figure 15: Cross-section al and button view of SPR joint: (a,b) s701 in T6 condition; (c,d) $s 701$ in T4x with 0 day of NA and $(e, f) s 701$ in $T 4 x$ with 32 days of NA.

Components made with s 701 alloy could be SPR joined with other materials in its $\mathrm{T} 4 \mathrm{x}$ s tate. The component could achieve full strength potential after paint baking process. Hence, s 701 in T4x temper with good mechanical property stability and improved ductility opens the opportunity to mechanically fastened using SPR even when positioned in the bottom stack. In real applications, actual alloy grades, stack up and gauge combinations may vary depending on applications. For instance, in a potential B pillar application in an aluminum intensive vehicle, it was likely to have a $6 \mathrm{xxx}$ body side outer, $6 \mathrm{xxx}$ B pillar outer and 7xxx B pillar 
inner forming a 3T stack. The rivet and die selection would need to be adjusted to accommodate each scenario.

\subsection{Trial results}

One recent example of implementing high strength s 701 alloy in an automotive application is Nio Inc. on their ES6 vehicle. There are a total of seven part including ski rails, B pillar reinforcements $\mathrm{LH} / \mathrm{RH}$ and 3 floor cross members as illustrated in Figure 16.

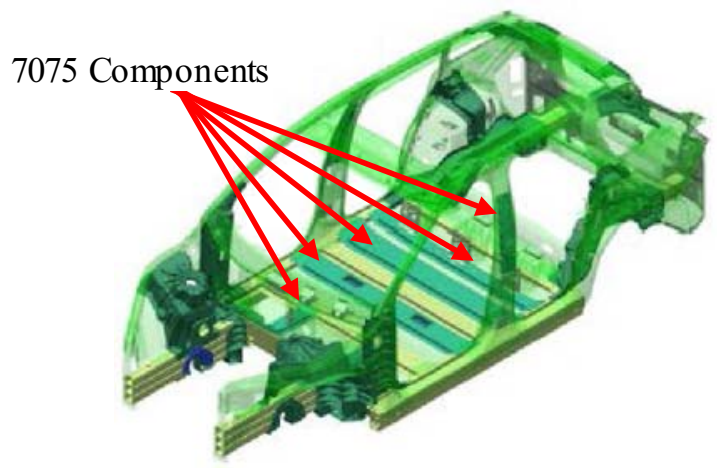

Figure 16: Overview of AA7075 alloy applications in Nio ES6.

These seven 7075 components replaced parts previously made with 6xxx alloys in ES8 with a total mass of 7.7 $\mathrm{kg} / \mathrm{vehicle}$. The high strength $\mathrm{s} 701$ alloy allowed all parts to be down gauged by $10-25 \%$. As a result, an average of $20 \%$ weight saving was achieved [3]. Novelis and Nio jointly developed the hot stamping process, artificialaging practice and corrosion mitigation strategy. A B pillar reinforcement made with Novelis s701 alloy after hot stamping was sectioned and evaluated to determine its mechanical properties. Figure 17 shows the mechanical properties from various locations of hot stamped part using sub-size samples due to part geometry.

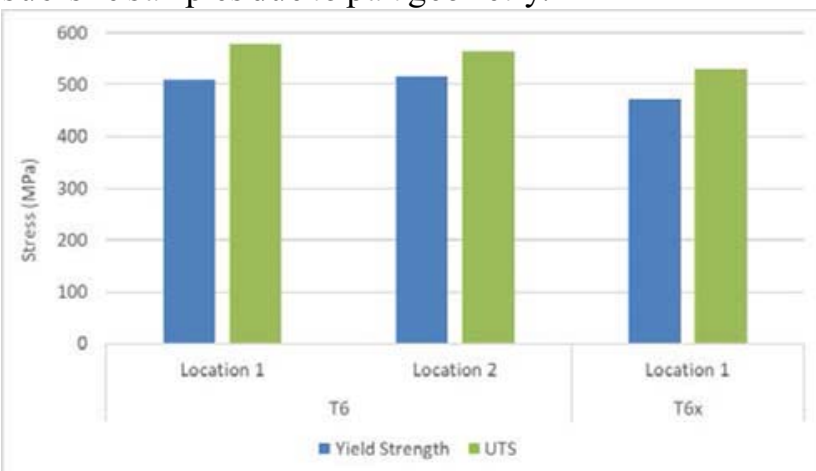

Figu re 17: Mechanical prope rty from parts made with Novelis s701 alloy.

The part was able to achieve 500MPa yield strength in T6 condition and 480MPa yield strength in T6x temper under a simulated paint bake condition of $185^{\circ} \mathrm{C} / 20$ minutes. A cons ervative approach employed by customers to simulate metal exposure during paint bake. The mechanical properties achieved were higher than targets and acceptable. The stamped part also shown good SPR performance with $0 \%$ crack rate when joined with adjacent aluminum components. In summary, through hot stamping process and accelerated aging practice, Nio is able to reduce their production cycle time, cost and improve SPR performance and successfully implemented AA7075.

\section{Conclusions}

S701 (AA7075) alloy can be a preferred solution for automotive light weighting especially to replace advance high strength steels (AHSS). It can be used for intrusion prevention and strength driven applications such as door intrusion beams, B pillars, floor cross-members etc.

S701 can be formed into complex geometry using hot stamping process.

An accelerated aging practice tailored to automotive process has been demonstrated. It will reduce artificial aging time from 24 hours to 1 hour.

The localized corrosion test results of the new accelerated ageing practice showed pitting corrosion morphology with the maximum pit depth less than $150 \mu \mathrm{m}$.

The new accelerated aging practice exhibited similar SCC resistance as compared to conventional in-s ervice temper T6+PB.

The new proposed accelerated aging practice stabilizes the material after hot stamping and maintains good ductility. This allows s 701 alloy to be mechanically joined using SPR and possibly other joining techniques with deformation involved.

With the new proposed accelerated aging practice, S701 alloy can achieve similar strength level as conventional aging and is robust when expos ed to automotivepaint bake cycle with extended time.

\section{Acknowledgement}

The authors gratefully acknowledge the contributions of the following:

Duane Bendzinski, Rahul Kulkarni, Raj Talla, Rashmi Mohanty, Yan Lin, Gan Ming, W onJun Kim, Kevin Ryan, Anna Janoff, Kyle Dasch, Jason Leszczewicz and all colleagues from Novelis Asia and NGRTC who supported the project.

Babak Shalchi from Canmet MATERIALS, Canada for his support on the TEM work.

David Head and Matthew Smith from Stanley Engineering for their SPR experiment.

Gary Denton, Leon Kaunitz Xuan Tang, Zhong Chen and Daniel Saltzmann from Nio for their support on hot stamping trials.

\section{References}

[1] WARDSAUTO, "2015 WARDSAUTO Survey," Dupont, 2015.

[2] J. Stanley and D. Lege, "Advances in aluminumalloy products for structural applications in transportation," Journal De PhysiqueIV, v3, pp. 179190, 1993.

[3] G. Denton, "The NIO ES8 \& ES6," in Europe Car Body, Bad Nauheim, 2019. 
[4] N.R.Harris on and S.G.Luckey, "Hot Stamping of a B-Pillar Outer from High Strength Aluminum Sheet AA7075," SAE International, pp. doi:10.4271/201401-0981, 2014.

[5] J. Parnell and L.Blayden, "Forming High Strength Bumpers from Aluminum Sheet," SAE Technical Paper 780141, p.doi:10.4271/780141, 1978.

[6] H. Wang, Y.B.Luo, P. Friedman, M.H.Chen and L.Gao, "Warm forming behavior of high strength aluminum alloy AA7075," Trans. Nonferrous Met. Soc. China, pp. 1-7, 2012.

[7] J.M.Papazian, "The effects of warm working on aluminum alloy 705-T651," Materials Science and Engineering, pp. 223-230, 1981.

[8] M.Kumar, N.Sotirov and C.M.Chimani, "Investigations on warm forming of AW-7020-T6 alloy sheet," Materials Processing Technology 214, pp. 1769-1776, 2014.

[9] A.Kraly, D. Vipava, F. Grabner, N. Ross and M. Kumar, "Hot Stamping Process of Aluminum 7xxx Sheets, Simulative Investigation," in Neuere Entwicklungen in der Blechumformung, Stuttgart, 2016.

[10] J. Li, Z. Peng, C. Li, Z. Jia, W. Chen and Z. Zheng, "Mechanical properties, corrosion behaviors and micros tructures of 7075 aluminumalloy with various aging treatments," Trans. Nonferrous Met. Soc. China 18, pp. 755-762, 2008.

[11] N. Harrison, S. Luckey, B. Cappuccilli and G. Kridli, "Paint Bake Influence on AA705 and AA7085," SAE Technical Paper, pp. doi:10.4271/2017-01-1265, 2017-01-1265.

[12] J. Park, "Influence of retrogression and re-ageing on the strength and stress corrosion resistance of aluminium alloy 7075-T6," Mater Sci Eng A, pp. 223-231, 1988.

[13] A.Keci, N. Harrison and S. Luckey, "Experimental Evaluation of the Quench Rate of AA7075," SAE TechnicalPaper, pp. 10.4271/2014-01-0984, 2014.

[14] L.K.Berg, D. Schryvers and L. Wallenberg, "GPZones in Al-Zn-Mg Alloys and their role in Artificial Aging," Acta Mater, p. vol4, 2001.

[15] J. Hatch, "Aluminum: Properties and Physical Metallurgy 1stedition," 1984,p. 51.

[16] S. Lim, I. Eun and S. Nam, "Control of Equilibrium Phases $(\mathrm{M}, \mathrm{T}, \mathrm{S})$ in the Modified Aluminum Alloy 7175 for Thick Forging Applications," Materials Transactions, Vol. 44 No.1, pp. 181-187, 2003.

[17] A. Chemin, D. Marques, L. Bisanha, A. Motheo and W. F. Ruchert, "Influence of A17Cu2Fe intermetallic particles on the localized corrosion of high strength aluminum alloys," Materials and Design, pp. 118123, 2014.

[18] G.Liu, G.Zhang, X.Ding, K.Chen and J. Sun, "Dependence of fracture toughness on multiscale second phase particles in high strength Al alloys," Materials Science and Technology, no. 19, pp. 887896, 2003.
[19] R.Ghiaasiaan, B. Amirkhiz and S.Shankar, "Quantitative metallogrpahy of precipitating and s econdary phases after s trengthening treatment of net shaped casting of Al-Zn-Mg-Cu (7000) alloys," Materials Science \& Engineering A, vol. 698, pp. 206-217, 2017.

[20] F.Andreatta, H. Herryn and J. Wit, "Corrosion behaviour of different tempers of AA 705 aluminium alloy," Electrochimica Acta, pp. 2851-2862, 2004.

[21] P. Rout, M.M.Ghosh and K.S.Ghosh, "Effect of solution $\mathrm{pH}$ on electrochemical and stress corrosion cracking behaviour of a 7150 Al-Zn-Mg-Cu alloy," Materials Science \& Engineering A, pp. 156-165, 2014.

[22] C.Altenbach, S. C., U.A.Mercado, J.P.Suuronen, D.Zander and G.Requena, "Synchrotron-based holotomography and X-ray fluorescence s tudy on the stress corrosion cracking behavior of the peak-aged 7075 aluminum alloy," Journal of Alloys and Compounds, p. 152722, 2020.

[23] M. Jackel, T. Grimm, R. Niegsch and W. Drossel, "Overview of Current Challenges in Self-Pierce Riveting of Lightweight Materials," in 18th International Conference on Experimental Mechanics, Brus sels, 2018.

[24] J. Staley, "Effect of Natural Aging Interval, Preaging and Heating Rate on the Aging Characteristics of 7075," Alcoa Laboratories, Pits burg, 1975.

[25] X. Varone, "New Aluminum Alloys in Electric Vehicles," in Materials in Car Body Engineering, Bad Nauheim, 2018.

[26] A.C.U.Rao, V.Vasu, M.Govindaraju and K. Saisrinadh, "Stress corrosion cracking behaviour of 7xxx aluminum alloys: A literature review," Trans. Nonferrous Met. Soc. China, pp. 1447-1471, 2016.

[27] F.E.Watkins on and J. Scully, "The Stress-Corrosion Cracking of a High Purity Al-6Zn-3Mg Alloy," Corrosion Science, pp. 905-924, 1972.

[28] J.Zuo, L. Hou, J.Shi, H. Cui, L. Zhuang and J. Zhang, "Enchanced plasticity and corrosion resistance of high strength Al-Zn-Mg-Cu alloy processed by an improved thermomechanical processing," Journal of Alloys and Compounds, pp. 220-230, 2017.

[29] N. Holroyd and G.M.Scamans, "Stress Corrosion Cracking in Al-Zn-Mg-Cu aluminumalloys in saline environments," Metallurgical and Materials Transactions A, pp. 1230-1253, 2013.

[30] S.P.Knight, N.Birbilis, B.C.Muddle, A. Trueman and S.P.Lynch, "Corrolations between intergranular stress corrosion cracking, grain-boundary microchemistr, and grain-boundary electrochemistry for Al-Zn-Mg-Cu alloys," Corrosion Science, pp. 4073-4080, 2010. 